DOI: $10.20472 / \mathrm{IAC} .2017 .33 .063$

HAN EOL RYU

Korea Institute for Industrial Economics and Trade, Korea, Republic of

\title{
ECONOMIC EFFECTS OF STANDARDS HARMONIZATION BETWEEN TECHNOLOGICALLY ASYMMETRIC COUNTRIES
}

\begin{abstract}
:
This paper examines the economic effects of harmonizing standards between technologically asymmetric countries, and the optimal harmonization policies. It sets up a simple three-firm, three-country model in which each country adopts different standards. The difference in standards incurs conversion costs to each firm for the foreign market access and harmonization through the FTA TBT agreement removes such costs between member countries. The paper shows that harmonization of standards with the technologically more or less advanced country always increases the consumer surplus and the social welfare. In addition, the producer surplus will increase if the harmonization partner country has a higher technology level while it may decrease if the partner has a lower technology level. The paper also shows that if most of the domestic exporting goods are in the sectors with high conversion costs, harmonizing standards with the technologically more advanced country is prioritized. If they are in the sectors with low conversion costs, harmonizing with the less advanced country is prioritized. Such strategies, moreover, should be emphasized under a higher technology asymmetry among the countries.
\end{abstract}

\section{Keywords:}

Standards, Harmonization, Technology Asymmetry, Technical Barriers to Trade

JEL Classification: F12, F13, L50 